\title{
Integrating Local Literature in Teaching English to First Graders under K-12 Curriculum
}

\author{
Lota O. Florentino \\ St. Louis University, Baguio City, 2600, Philippines
}

\begin{abstract}
The K to 12 curriculum has already been implemented and part and parcel of it is the MTB-MLE program in which the mother tongue of the learner is used as a medium of instruction and also taken as a subject. As this program advocates the instilling of cultural heritage in the learner, this study explores on integrating local literature (Cordilleran) in the teaching of English. This is done by looking at several factors affecting the choices of teachers, determining the weaknesses of the learners particularly in English grammar awareness, and creating a sample appropriate activity to address the identified weak areas. Data were collected primarily via survey, inter-rater and summative tests and treated through descriptive statistics. Results show that values laden, motivational, in line with the subject matter, substantial, and culturally relevant literary pieces top the line of preferred literature. Also, results of the test in determining weak areas show a big percentage of learners finding the test on identified competencies easy. However, percentage of those who find it difficult is still at an alarming level. Resulting to this is the making of a sample activity created with special emphasis on illustrative activities. The local literature is selectively integrated in the prototype lesson guide issued to the teachers in line with the objectives and the theme embracing each of the given activities.
\end{abstract}

Index Terms-K-12 curriculum, MTB-MLE, Cordilleran literature, grammar awareness, identified weaknesses, descriptive statistics, prototype plan, illustrative activities, visual learning

\section{BACKGROUND OF THE STUDY}

Historically, the Philippine education system has undergone several modifications to meet continuously rising local and global demands for quality education. However, this is the only time that it has undergone dramatic calibration since the change affects both basic and higher education levels. The number of years from elementary to high school used to be ten (10) only, but under the newly implemented $\mathrm{K}$ to 12 curriculum, the number of years increased to twelve (12), six (6) in the elementary and six (6) in the high school. The new curriculum has been made legal by the creation of Republic Act No. 10533, an act enhancing the Philippine Basic Education System by strengthening its curriculum and increasing the number of years for basic education, appropriating funds therefore and for other purposes. It is otherwise known as Enhanced Basic Education Act of 2013 approved on May 15, 2013, and which took effect on June 8, 2013.

Section 4 of the Act labeled Enhanced Basic Education Program stipulates that for kindergarten and the first three (3) years of elementary education, instruction, teaching materials and assessment shall be in the regional or native language of the learners. It further stipulates that for purposes of this Act, mother language or first Language (L1) refers to language or languages first learned by a child, which he/she identifies with, is identified as a native language user of by others, which he/she knows best, or uses most.

Section 5 under Curriculum Development stipulates that the curriculum shall be learner-centered, inclusive and developmentally appropriate; relevant, responsive and research-based; culture-sensitive; contextualized and global; adhere to the principles and framework of MTB-MLE which starts from where the learners are and from what they already knew proceeding from the known to the unknown; instructional materials and capable teachers to implement the MTB-MLE curriculum shall be available; flexible enough to enable and allow schools to localize, indigenize and enhance the same based on their respective educational and social contexts. The production and development of locally produced teaching materials shall be encouraged and approval of these materials shall devolve to the regional and division education units.

Another new program being implemented simultaneously with the K-12 curriculum as it is part and parcel of the Enhanced Basic Education Program is MTB-MLE. As has been advocated by its proponents and as mentioned in the republic act, this is the use of the mother tongue as a subject and as a medium of instruction in the first three (3) grades. This being said, it can be seen that so much is placed on the shoulders of instructional materials developers. Since this is a new curriculum, therefore, it requires such that can cater to the needs of the learners per K-12 and MTB-MLE standards.

To give a bird's eye view of the steps in the process of developing curriculum and teaching/learning materials that are educationally sound, acceptable to education authorities and helpful for teachers, Susan Malone (2012) developed the following flowchart: 


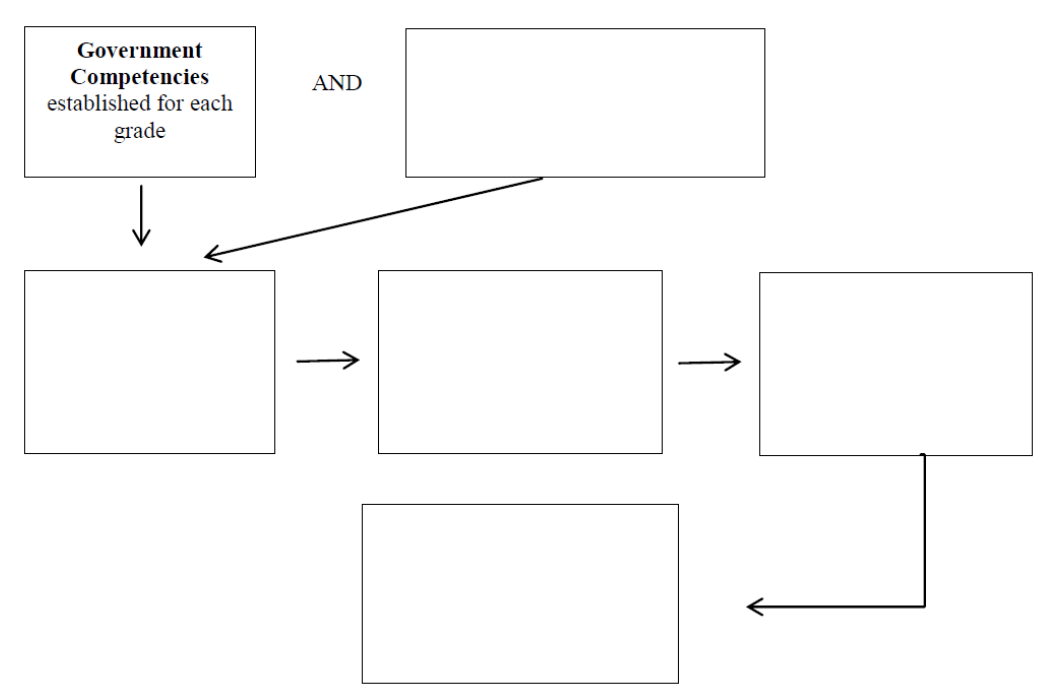

It is worthy to note at this point that in K-12's first leg of implementation, the mother tongue, like the Ilocano language, is used as a subject and as a medium of instruction. English is also taken as a subject. The K-12 list of competencies in the Mother Tongue has already been issued to schools. However, as of this writing, the competencies in the English language has yet to be completed, but it is safe to assume that the competencies used for the Mother Tongue subject is similarly used for the English Language subject.

The aim of this study is to develop English language instructional materials for first graders that are within the standards of the new curriculum. Tomlinson (2012) explicated that materials can be informative (informing the learner about the target language), instructional (guiding the learner in practicing the language), experiential (providing the learner with experience of the language in use), eliciting (encouraging the learner to use the language) and exploratory (helping the learner to make discoveries about the language). As different learners learn in different ways (Oxford 2002), the ideal materials aim to provide all these ways of acquiring a language for the learners to experience and sometimes select from (Tomlinson 2012). To achieve this objective, the use of literature as a technique for teaching both basic language skills (i.e. reading, writing, listening and speaking) and language areas (i.e. vocabulary, grammar and pronunciation) has become very popular in the field of language learning and teaching. Langer (1997, as cited in Shang, 2006) states that literature is used with EFL learners because it taps what they know and who they are, and literature is a particularly inviting context for learning both a second/foreign language and literacy. To further back this view, many teachers consider the use of literature in language teaching as an interesting and worthy concern (Sage, 1987). In fact, the literature-based approach supports integrated skills and, as a result, activities usually target reading, writing, listening, and speaking all in one (Seghayer, 2003). According to Fitzgerald (1993), literature can be the vehicle to improve learners' overall language skills. It can "expose students to a wide variety of styles and genres" (p.643). It is in literature that "the resources of the language are most fully and skillfully used" (Sage, 1987.p.6.) Abulhaija (1987, as cited in Shang, 2006) states that teaching language in isolation from literature will not move students toward mastery of the four language skills.

Based on experience, it can be noticed from among the young learners of today that most of them know well all about the literatures of other countries. This is primarily because most teachers make use of materials with foreign literature in them in teaching since they are the most easily available and accessible. However, the K-12 curriculum mandates the use of the mother tongue in teaching most subjects in schools, including English; but, based on studies, instructional materials developed out of local pieces are the hardest to find and create. Since the thrust of the K-12 is instilling in the pupils their cultural heritage, the best source is the local literary pieces.

Objectively, through this research, the integration of local literature (Cordilleran) in the lessons of these pupils will possibly be made into fruition. The development of instructional materials that cater specifically to a certain locality generally adheres to a pre-established process (see flowchart by Malone on page 2). To efficiently complete the process, the study focused on answering the following concerns: 1) what local literature (Cordilleran) can be used in teaching English to first graders as preferred by teachers in the first grade; 2) what weaknesses of the pupils in terms of English grammar awareness are identified, specifically on a) identifying proper nouns, b) giving the proper names of nouns, c) writing proper nouns; and 3) what activities can be made to address the identified weaknesses.

With the findings of this research, future teachers will be made aware of the Cordilleran literature that can be appropriately used for instructional materials development for English language teaching. Moreover, awareness amongst younger generation of Cordillerans on the existence of their own literature is enhanced, thus instilling in them the beauty of their cultural heritage. Also, teachers of MTB-MLE will be more open to different ways in carrying out their task as facilitators of learning, especially on grammar awareness competencies. Future ESL/EFL educators will 
likewise be exposed to different competencies of beginners in an ESL classroom under the K to12 curriculum, thus making them more effective and critical in selecting instructional materials.

\section{RESEARCH FRAME WORK}

For the study to work effectively, the following theories of learning are considered as its underpinnings.

The Social Development Theory of learning was introduced by Lev Vygotsky who "argues that social interaction precedes development; consciousness and cognition are the end product of socialization and social behavior". (Discroll, 1994) Moreover, Vygotsky focused on the connections between people and the socio-cultural context in which they act and interact in shared experiences. According to Vygotsky, humans use tools from their culture, such as speech and writing, to interact with their environment. Children use these tools to communicate their needs. Vygotsky believed that the internalization of these tools led to higher thinking skills (Driscoll, 1994). This is one of the learning theories that guide the MTB MLE program. This also guides this study as it mentioned the use of "tools" from the culture of the children for them to learn how to communicate. Part of those tools could be the literature of their culture. Since this research aims at integration of Cordilleran literature in the teaching of English, this theory is apt to support this aim. As the pupils learn the basic concepts of grammar, they can also be in contact with different literatures that reflect the richness of their own culture. They will become socially aware of their roots through the tales that they will encounter.

Winitz (1981) states that the approach Comprehension-based is a methodology that is listening comprehension. Accordingly, listening for the student is very important and is viewed as the basic skill that will allow speaking, reading, and writing to develop spontaneously over time, given the right condition. Learners should begin by listening to meaningful speech and by responding nonverbally in meaningful ways before they produce any language themselves. Learners should not speak until they feel ready to do so; this results in better pronunciation than if the learners are forced to speak immediately. This theory becomes important to the study because of the way of teaching in the first grade. The pupils' listening skill is eventually improved because the tales to be read to them are in English. With this, they are exposed to the second language by listening to it. Undeniably, the teacher will have to use bridging for the pupils to understand certain vocabularies from the reading. However, as the theory indicates, this is helpful since the pupils will know how the words and statements are uttered properly so they can follow the manner of speaking as how they were spoken to them.

The focus of Content-Based Instruction approach is not on the language itself but more on what is being taught using the language. The language becomes the medium through which something new is learned. In the CBI, pupils learn English by using it to learn new content. (Bilash, 2009) In the case of the study, pupils will use the English language to learn their culture via the literatures that they are going to study. However, since the pupils are still being introduced to the English language, it cannot be avoided that teachers will use bridging to get the information across. The theory behind CBI is that when pupils are engaged with more content, it will promote intrinsic motivation. (Bilash, 2009) Since the pupils will be using their own literature to learn English it is the hope of the researchers that they will be more comfortable and will be more expressive. This approach is very flexible when it comes to the content which is to be used in teaching that it's worth looking into for this study. Classes in the K-12 are somehow conducted just like what this approach is saying. As stated, one objective of the study is for literature to become part of the content of the teacher's teaching materials. By making use of the tales, the learning process becomes interactive since the pupils can now relate to the subject (content) being talked about.

The Literature-based approach is one of the recent additions to the approaches in teaching English as a second language. One of the benefits of this approach is its flexibility. Any literature can be utilized as long as it includes the components of the target language that is going to be taught by the teacher. Moreover, the literature-based approach supports integrated skills and, as a result, activities usually target reading, writing, listening, and speaking all in one (Seghayer, 2003). Part of the flexibility of this approach, grammar can be given emphasis on the lesson just as culture is being highlighted because of the cultural undertones of the literature being utilized. Because of the nature of this teaching approach, it is imperative to include it as part of the study's framework.

Visual thinking is a learning style where the learner better understands and retains information when ideas, words and concepts are associated with images or pictures that the learner can easily relate with. The Visual Learning Theory is very relevant in today's generation of learners. Previous researches tell us that majority of the pupils need to see photos and images of the information for them to learn it. (Inspiration Software, Inc., 2013) Also, seventy-five percent of all information processed by the brain is derived from visual formats (Williams, 2009). With these givens, it is important to use Visual learning Theory as one of the theoretical background when developing lesson plans. This theory is highly significant to the pupils since it can help in making connections on how given information is related to an image shown to them. It can also help in organizing and analyzing information. Through organization, the pupils can then see relationships and patterns about what they are learning. Naturally, this way of learning can help pupils integrate new knowledge because it motivates their imaginative skills to visualize the information. Thus, it can also help in the development of the pupils' critical thinking. By linking what they hear and what they see, it helps the pupils understand relationships of related details.

\section{METHODS}


Data for this study were collected via a survey, inter-rater test, and a summative test done in Lucban Elementary School in Baguio City. Three hundred one of their first graders and their ten teachers in the first grade were made the subjects. Data gathering was set to motion on the third quarter of the school year since it was only then that English was started to be taught to the pupils. The first part of the study was the surveying of the literary pieces. A list of 27 possible literatures which were numbered was provided for the grade one teachers to study. They ranked each literary piece according to their preference basing on several factors presented. The weaknesses of the learners in English grammar awareness were then measured by way of a summative test. In making the test, a list of competencies laid out by the Department of Education (DepEd) was referred to. After identifying these weaknesses, sample of the tasks and activities to address the weaknesses integrating the preferred literature was made. The study was quantitative and qualitative. Descriptive statistics was used in the first part (frequency, mean, and ranking). The literary pieces and factors affecting the teachers' choices were ranked accordingly by the teachers themselves.

The second part was the administering of the summative test. The learners were given a test after their lessons under identified competencies (e.i. identifying proper nouns; naming proper nouns; etc.). Before the test was administered, an inter-rater validity test was given to the teachers to see if the prepared summative test was appropriate to the pupils' level. The result of the summative test was treated using descriptive statistics, too. The grading system of elementary public schools issued by the DepEd in interpreting the raw scores was utilized. This grading system was introduced by then Education Secretary Edilberto C. de Jesus. It states that the passing rate should be at $75 \%$ of the overall total score. (Rimando, 2004) Thus, this was followed in assessing the results of the test.

Basing on the results of the test, a sample task was made and this comprised the third phase of the study. This task was geared toward a more visual approach to learning. The task was supposedly made to improve the identified weak areas.

\section{RESUltS}

The first phase of the research was to know the preferences of teachers as to the literature to be integrated. Ten teachers in the first grade were presented twenty-seven (27) stories to choose from. After reading the stories they were asked to rank it from 1 to 27,1 being their most preferred and 27 their least preferred.

TABLE 1.0

TOP 10 PREFERRED STORIES

\begin{tabular}{llll}
\hline Title of the Story & Raw scores & Average & Rank \\
\hline 1. The Squash Seed & 65 & 6.5 & 1 \\
2. Palpal-ama and Palpal-iking & 95 & 9.5 & 2 \\
3. The Origin of Rice & 98 & 9.8 & 3 \\
4. The Star Children & 98.5 & 9.85 & 4 \\
5. The Creation and the Peopling of the Earth & 100 & 10 & 5 \\
6. How the climate Change & 101 & 10.1 & 6 \\
7. The First Tools & 110.5 & 11.05 & 7 \\
8. Why the Crab doesn't have a Head & 112 & 11.2 & 8 \\
9. Malekdon & 114.5 & 11.45 & 9 \\
10. The Crow and the Lizard & 117 & 11.7 & 10 \\
\hline
\end{tabular}

Table 1.0 shows the top ten most preferred stories. To find the top ten, percentages and averaging were utilized. First, the ranks given by the teachers to each story were added, hence the raw scores. They were then divided by ten to get the average, after which ranking was made from lowest to highest, the lowest ten being the top ten most preferred literary pieces.

TABLE 1.1

FACTORS TO CONSIDER IN CHOOSING A STORY

\begin{tabular}{lll}
\hline Factors to consider & Ave & Significance \\
\hline 1. There are morals and values reflected on the literary piece. & 1.6 & Significant \\
2. The piece has a great motivational factor. & 1.8 & Significant \\
3. The contents are in line with the subject matter. & 1.8 & Significant \\
4. The substance of the literary piece as a teaching material. & 1.9 & Significant \\
5. The piece can be an aid for the social awareness of the pupils. & 2 & Significant \\
6. The significance of the piece to the cultural background of the pupil. & 2.1 & Significant \\
7. The appeal of the imagery presented by the piece. & 2.3 & Significant \\
\hline
\end{tabular}

Next determined were the factors that affected the teachers' decision in ranking the stories (Table 1.1). Another set of questionnaire designed to answer the aforementioned query was included. This questionnaire was imperative to the progress of the study as the literary pieces would then be integrated in the lessons of the pupils. Each factor was assessed from 1 to 4 according to its significance: 1 being the most significant; 2 , significant; 3 , less-significant; and 4 being the least significant. 
TABLE 2.0

INTER-RATER VALIDITY TEST RESULTS

\begin{tabular}{lll}
\hline Test & Percentage & Rank \\
\hline I: Naming Proper nouns & 3.9 & Easy \\
II: Identifying Proper nouns & 3.4 & Satisfactory \\
III: Writing Names of Proper nouns & 2.7 & Satisfactory \\
Overall percentage: & 3.3333 & Satisfactory \\
\hline
\end{tabular}

Table 2.0 shows the result of the inter-rater validity test given to the teachers to assess if the summative test was indeed suitable to the level of the test takers. The assessment followed the following scale: 5 -very easy; 4 -easy; 3 satisfactory; 2 -difficult; 1 -very difficult.

The results of the summative test show the weaknesses of the first graders in the aforementioned competencies as shown in the succeeding tables.

TABLE 2.1

TEST I: NAMING PROPER NOUNS

\begin{tabular}{|c|c|c|c|}
\hline Score & Frequency & Percentage & Rank \\
\hline Easy & 209 & $69 \%$ & 1 \\
\hline Satisfactory & 44 & $15 \%$ & 2 \\
\hline Difficult & 13 & $4 \%$ & 4 \\
\hline Very Difficult & 35 & $12 \%$ & 3 \\
\hline Mean $=4.32$ & & & \\
\hline
\end{tabular}

TABLE 2.2

TEST II: IDENTIFYING PROPER NOUN

\begin{tabular}{lccc}
\hline Score & Frequency & Percentage & Rank \\
\hline Easy & 120 & $39.9 \%$ & 1 \\
Satisfactory & 68 & $22.6 \%$ & 2 \\
Difficult & 59 & $19.6 \%$ & 3 \\
Very Difficult & 54 & $17.9 \%$ & 4 \\
Mean = 3.81M & DE = Satisfactory & & \\
\hline
\end{tabular}

TABLE 2.3

TEST III: WRITING NAMES OF PROPER NOUNS

\begin{tabular}{llll}
\hline Score & Frequency & Percentage & Rank \\
\hline Easy & 187 & $62 \%$ & 1 \\
Satisfactory & 37 & $12 \%$ & 3 \\
Difficult & 34 & $11 \%$ & 4 \\
Very Difficult & 44 & $15 \%$ & 2 \\
Mean =3.8 & DE = Satisfactory & & \\
\hline
\end{tabular}

Tables 2.1, 2.2, and 2.3 all show the level of the first graders based on their scores in the summative test. The ranking was based on $75 \%$ passing rate (Rimando, 2004). Such is the case when one gets $75 \%$ of 5 , one gets 3.75 as the passing mark for a test that has five items. Each test had five (5) questions, and each question was focused on a specific proper noun. If the learner got 5 in a certain test, then that test was easy for him. If he got a 4 that was still satisfactory, but when he got 3 to 0 then he failed the test, which in turn, could mean a weakness.

Moving on phase three of the study, to address the identified weaknesses, a sample material was made. Current lesson guides were studied. A part that contained a song was picked; instead of singing songs that are not culturally based, the learners would listen to a local story (Cordilleran). The chosen literature was seen fit to the theme of the lesson guide. The following table shows an excerpt of the entire lesson plan. This only shows the part where the literary piece was integrated. 
TABLE 4.0

SAMPLE MATERIAL (EXCERPT OF A LESSON PLAN)

\begin{tabular}{|c|c|}
\hline \multicolumn{2}{|c|}{ Theme: $\quad$ Me and My Family } \\
\hline \multicolumn{2}{|c|}{$\begin{array}{l}\text { Target skills: } \\
\text { At the end of the lesson, the students should be able to: } \\
\text { Expressive objectives: } \\
\text { - Realize that the body parts can do a lot of things } \\
\text { - Appreciate that story-telling, singing songs, and reciting rhymes can be fun } \\
\text { Instructional objectives: } \\
\text { - Oral language: Listen and share about him/herself } \\
\text { - Phonological Awareness: Recognize words that rhyme } \\
\text { - Listening Comprehension: Listen and share about him/herself; follow directions } \\
\text { - Vocabulary and Grammar : Recognize, Identify, and give examples of naming words (body parts) }\end{array}$} \\
\hline \multicolumn{2}{|c|}{\begin{tabular}{l|l}
$\begin{array}{l}\text { Suggested Number } \\
\text { of Minutes }\end{array}$ & WEEK 5 - Day 1 Lesson Plan \\
\end{tabular}} \\
\hline \multirow[t]{3}{*}{10 mins } & $\begin{array}{l}\text { I. Pre-Assessment } \\
\text { Conduct a game of "touch your body part" } \\
\text { Have the class point to a body part } \\
\text { Ex. Can you touch your nose? }\end{array}$ \\
\hline & $\begin{array}{l}\text { II. Objectives: } \\
\text { - Recognize parts of the body } \\
\text { - Understand the story of the "The Squash Seed" }\end{array}$ \\
\hline & $\begin{array}{l}\text { III. Subject Matter and Materials } \\
\text { Subject Matter: Body parts, nouns } \\
\text { Materials: body parts puzzle, pictures }\end{array}$ \\
\hline 5 mins & $\begin{array}{l}\text { IV. Procedure } \\
\text { 1. Activating Prior Knowledge; } \\
\text { Ask the children to form a puzzle of a boy and a girl using different body parts (paper cut-outs) } \\
\text { 2. Presentation: } \\
\text { The teacher will read the story to the children while showing drawings of events from the story. To connect it to } \\
\text { procedure number } 1 \text {, the drawings must highlight/emphasize the different body parts of the characters shown in } \\
\text { the scene of events. } \\
\text { The Squash Seed } \\
\text { By: Andrew Kiley } \\
\text { Long ago, there was Gatan and Bangan, the two youngest children in the family, and the favorites of their parents. } \\
\text { All their requests were granted by their parents while their elder brothers and sisters were ignored. When the } \\
\text { parents died, the older children were happy because they can force Gatan and Bangan to work for them. Soon, the } \\
\text { two youngest children were treated like servants' by their older brothers and sisters. They were forced to work for } \\
\text { the others who did not work for themselves. From that day on they were treated very harshly. } \\
\text { One day, Gatan felt very sorry for his younger sister Bangan. He took her on his back and left home. On their way } \\
\text { they found a squash seed. They took it with them. Then it rained. They went to rest in a small cave. But before } \\
\text { they fell asleep, they stuck the squash seed in a tone crack. } \\
\text { The next day they saw that the squash seed had grown up and had many fruits. Bangan decided to cook some for } \\
\text { breakfast. When she opened the squash, she was surprised to find the inside full of rice. She took another one and } \\
\text { opened it and it, too, was filed with rice. They decided to build their house there. } \\
\text { A few years later, a famine occurred in the land. People had to buy rice from other places. The older brothers and } \\
\text { sisters were also affected so they went to buy rice as well. They were surprised to see that the people selling rice } \\
\text { were their youngest brother and sister. They presented themselves timidly and bought some rice. When Bangan } \\
\text { and Gatan saw there brothers and sisters were sorry for what they did, and Bangan and Gatan invited them to live } \\
\text { with them. After a long pause because of their shame, their brothers and sisters gratefully agreed to live with } \\
\text { Bangan and Gatan. }\end{array}$ \\
\hline \multirow[t]{2}{*}{10 mins } & $\begin{array}{l}\text { 3. Guided Practice: } \\
\text { Show the pictures and let the children identify the events in the story }\end{array}$ \\
\hline & $\begin{array}{l}\text { 4. Independent Practice } \\
\text { Identify the other nouns in the story }\end{array}$ \\
\hline
\end{tabular}

\section{DISCUSSION}

This study highlights the making of an appropriate instructional material at par with $\mathrm{K}$ to 12 standards utilizing local literature. Since the new curriculum is still newly implemented as of this writing, educators are quite in a quandary to find learning materials that are localized and or indigenized as dictated by the MTB-MLE program. The findings of this study demonstrate that it is indeed potentially probable to realize such goal as likewise carefully and sequentially explicated in the research.

The top ten preferred literary pieces chosen by the teacher-respondents themselves prove that there are indeed local materials, specifically Cordilleran, that are readily available to sustain the MTB-MLE inspired educational system. The choices of the respondents can only be explained by looking at the factors that affected such choices. It was found out that stories that reflect morals and values, the ones that motivate the learners, and stories whose content is in line with the subject matter topped the factors affecting the respondents' choices. Looking closely at these factors, it can be seen that the socio-cultural aspects of teaching and learning are manifested in them and the likelihood of the material to be used in a learner-centered activity or environment is always feasible. These ideas are clearly espoused by the Social 
development theory by Vygotsky. (Driscoll, 1994). The other factors reflect the idea of Content-Based Instruction. (Bilash, 2009). The factors were chosen from the list proposed by Eowyn Brown (2004) in her "Using Children's Literature with Young Learners" which was published in The Internet TESL Journal. Also considered was the Definition of a Literary Merit by Deborah Shepard in her article "Engaging Students with Literature - Curriculum Module for AP English Literature and Composition" published in The College Board in 2010. Based on the result, all the listed factors are worthy of consideration.

Moving on to the next phase of the research, before administering the summative test, an inter-rater validity test was conducted and the findings demonstrate the suitability of the items to the level of the test-takers. A number of teachers held that the test was easy for advanced pupils (pupils who can read) but it was difficult for the non-readers. In administering the summative test, a brief review on nouns was given and afterwards, the test was read to the learners for the benefit of those who are still hard up in reading English. This part of the research was also a concrete manifestation of the Comprehension-Based Approach. English classes in grade one are all dictations done by the teacher since most cannot read and speak in English yet. Listening comprehension then is the first skill that is enhanced before the other skills are introduced to the pupils. Looking at the result of the test, generally speaking, the pupils didn't manifest any difficulty in the first competency. In Table 2.1, 69\% of the pupils found it easy to name a proper noun and only $16 \%$ displayed a weakness. Table 2.2, however, shows that only $39.9 \%$ found identifying proper nouns easy and $37.5 \%$ found it either difficult or very difficult. The gap is quite close. Table 2.3 is almost at par with Table 2.1 showing $62 \%$ of the pupils could write names of proper nouns and only $26 \%$ were hard up in doing it. Nevertheless, this competency was still pegged at satisfactory since the overall mean offered a different interpretation. Basing on the results and the overall mean of each competency, it is safe to note that the curriculum is properly working but it still suggests possible improvement on the instructional level.

Illustrated on the last part of the result portion is the crafted lesson plan. The original lesson guide followed by the teachers is thematic and lessons are made on a weekly mode. The lesson plan was crafted in line with the theme and objective of the plan for week 5. Moreover, since it would be used in attaining the objectives of the lesson guide, the storytelling activity manifested the entire objective. As for the presentation, it underpinned the theory of visual learning. While the teacher was telling the story, illustrations depicting events from the story would be shown. Not only that, the purpose of the drawing was to show concrete examples of the lesson's objectives.

\section{CONCLUSIONS AND RECOMMENDATIONS}

Basing on the literature and data survey presented, developing instructional materials at par with K to 12 and MTBMLE standards undergoes a careful process of selection of materials and matching of such with identified learning outcomes and indicators. To be within standards, these materials have to be thematically in line with the thrusts of the current curriculum. The ten most preferred stories all manifest morals and values evident of human frailty and kindness. It can be gleaned from this a basic character of man that learners relate with which makes them retain information quickly and meaningfully. Factors such as motivation, in line with subject matter, substance, aiding social awareness, imagery, and cultural significance were also considered as significant in choosing these stories. The result of the summative test provides an impression that the $\mathrm{K}$ to 12 curriculum is working as indicated by the scores of the pupils. There are a greater percentage of pupils who find the competencies easy to tackle. However, since the percentage of pupils who still need improvement is still at an alarming level, it is important to develop a material that will address the specific needs of these pupils. As presented by the sample task, the integration of a local literature (Cordilleran) in the prototype plan or lesson guide issued to teachers is seen as a welcome innovation that will benefit the learners, especially in the Cordilleras, to make them rooted to their cultural heritage thus attaining the primary objective of the curriculum currently in place.

Basing on the above conclusions, in choosing a literary piece, an educator has to consider factors that manifest and are appropriate to the thrusts of the current curriculum to attain optimal learning. Lessons should also be presented more visually, meaning, teachers should have more effective visual aids. As visual learning theory states, pupils of today's generation tend to learn more if they visualize what they are learning. The use of visuals in education, although consistently shown to aid in learning, must be carefully planned, though, as the use of visuals that steer the learner to the exciting or entertaining aspects of presentation rather than encouraging thoughtful analysis of the underlying meaning may interfere with the intent of the lesson (Sherry, 1996). Pupils retain more information if their imagination is better stimulated. This theory also suggests that visual learning can help pupils learn to become more critical in studying and imbibing the lessons being discussed. This recommendation is supported by the presented sample lesson plan. Even if the lesson plan follows the prototype plan for English issued by the DepEd to Grade 1 teachers, this can be improved by integrating local literary pieces (in this study, Cordilleran, for that matter) and by including enhanced visual activities that can help in the discussion of the piece to improve identified weaknesses under specific competencies.

\section{ACKNOWLEDGMENT}

The author would like to acknowledge the following student-researchers for their valuable support in the success of this study: Amla, S.L., Dela Pena, M.T., Doligas, B., Lobo, R.I.M., Nga-awan, P., and Rillera, K. 


\section{REFERENCES}

[1] BILASH, O. (2009). Content-Based Instruction. Improving Second Language Education Retrieved February 21, 2012 from http://www2.education.ualberta.ca/staff/olenka.Bilash.

[2] BROWN, E. (2004). Using children's literature with young learners. The Internel TESL Journal. Retrieved on October 312012 from iteslj.org/Techniques/Brown_ChildrensLit.html.

[3] COADY, J. (1997). L2 vocabulary acquisition through extensive reading. In J. COADY and T. HUCKIN (Eds) Second Language Vocabulary Acquisition. Cambridge: Cambridge.

[4] DRISCOLL, M.P. (1994). Psychology of Learning for Instruction. Needham, MA: Allyn \& Bacon.

[5] FITZGERALD, J. (1993). Literacy and students who are learning English as a second language. The Reading Teacher, 46(8), 638-647. Retrieved August 06, 2007, from http://www.jstor.org.

[6] KRASHEN, S. (1989). "We Acquire Vocabulary and Spelling by Reading: Additional Evidence for the Input Hypothesis". The Modern Language Journal. Retrieved on October 312012 from http://onlinelibrary.wiley.com/doi/10.1111/j.15404781.1989.tb05325.x/abstract.

[7] LANGER, J. (1997). Literacy acquisition through literature. Journal of Adolescent and Adult Literacy, 40, 602-614. Retrieved August 06, 2007 from http://www.iteslj.org/Techniques/Shang-CBI.html.

[8] MALONE, S. (2012). Workshop on Bridging between languages in MTB MLE programs. MLE WS, Bangkok 2012.

[9] Official Gazette (2012). Features of the K-12 Curriculum. Retrieved February 25, 2013 from http://www.gov.ph/k-12/\#Features

[10] OXFORD, R. L. (2002). Sources of variation in language learning. In R. B. Kaplan (ed.), The Oxford Handbook of Applied Linguistics (3rd ed). New York: Oxford University Press, 245-252.

[11] RIMANDO, T.P. (2004) DepEd adopts new grading system for elementary, HS. Manila Bulletin Retrieved February 22, 2013 from http://www.mb.com.ph/node/171902\#.USY1SR0mdRI.

[12] SHANG, H. (2006). Content-based Instruction in the EFL Literature Curriculum. The Internet TESL Journal, Vol. XII, No. 11 Retrieved August 06, 2007 from http://www.iteslj./Techniques/Shang-CBI.html.

[13] SHEPARD, D. (2010). Engaging Students with Literature - Curriculum Module for AP English Literature and Composition. College Board - Inspiring Minds. Retrieved on October 30, 2012 from apcentral.collegeboard.com/apc/public/repository/ AP CM_Eng_Lit_differential_instruction.pdf.

[14] SHERRY, L. (1996). Issues in distance learning. International Journal of Educational Telecommunications, 1(4), 337-365. Retrieved December 26, 2001, from http://www.cudenver.edu/ lsherry/pubs/issues.html.

[15] STOKES, S. (2001). Visual Literacy in Teaching and Learning: A Literature Perspective. Electronic Journal for the Integration of Technology in Education vol. 1, no. 1. Retrieved on October 30, 2013 from http://ejite.isu.edu/Volume1No1/Stokes.html.

[16] TOMLINSON, B. (2012). Materials development for language learning and teaching. Cambridge Journals. Retrieved on October 30, 2013 from http//journals.cambridge.org.

[17] WILLIAMS, V. S., \& DWYER, F. (1999). Effect of metaphoric (visual/verbal) strategies in facilitating student achievement of different educational objectives. International Journal of Instructional Media, 26(2), 205-211. Retrieved September 14, 1999 from EBSCOhost database (Academic Search Elite).

[18] WINITZ, H. (1981). A reconsideration of comprehension and production in language training. In H. Winitz (Ed.), The comprehension approach to foreign language instruction (pp. 101-140). Rowley, MA: Newbury House.

Lota O. Florentino is a Filipino citizen, born in the Philippines on May 24, 1963. She is higher education instructor of English, Literature, Education, and Research subjects at Saint Louis University, Baguio City, Philippines. She is a PhD candidate having finished her academic requirements in $\mathrm{PhD}$ Language Education and currently writing her dissertation for the program in the same university. She holds a Bachelor's Degree in Elementary Education and a Master's Degree in Language Education. 